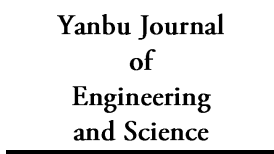

ISSN: 1658-5321
Vol. 3, October $2011(1432 \mathrm{H})$ www.yjes.org.sa

\title{
NON LINEAR SIMULATION MODEL OF ENGINE RESPONSE DUE TO PISTON-SLAP
}

\author{
Nadim A. Emira ${ }^{1}$ and M. Riad Ghazy ${ }^{2}$ \\ 1 Yanbu Industrial College, PO Box: 30436, Yanbu Al-Sinaiya 21477, Kingdom of Saudi Arabia, On leave from Mechanical Design \\ \& Production Department Faculty of Engineering, Zagazig University, 44511 Zagazig, Egypt, E-mail: nemira@yic.edu.sa \\ 2 Mechanical Design \& Production Department, Faculty of Engineering, Zagazig University, 44511 Zagazig, Egypt, E-mail: \\ Ghazy_Moh_riad@yahoo.com
}

\begin{abstract}
Piston slap is a transient impact phenomenon existing in the reciprocating engine. It comprises a major cause of the complex transient vibration of the engine. In order to correlate the piston-slap impact with the slap-induced vibration and consequently find out an effective approach for the engine dynamic behavior simulation for improved prediction of engine vibration response, an investigation for theoretical modeling is proposed.

The piston-slap phenomenon is discussed from the viewpoint of engine mechanics. Based upon this, a nonlinear model is developed to simulate the slap-induced vibration response. Using numerical integration procedure, the cylinder liner vibration response and its correlation with the piston-slap are reasonably evaluated.
\end{abstract}

Keywords: Piston slap, Liner vibration

\section{INTRODUCTION}

In order to develop an effective analyzing and monitoring approach by using the engine vibration, many efforts have been made in recent years. Among these approaches, evaluation of the impact excitation inside the engine and its correlation with the engine vibration is gaining more and more attention $[1,2,3$ and 4], etc. The main concern is to reduce engine noise which is originated from two sources, namely combustion and mechanical noise sources. The mechanically oriented noise source is primarily accredited to mechanical impacts occurring inside the engine; mainly bearing and piston impacts. Piston impact is usually referred to as piston slap.

Piston slap is the impact between the piston and the cylinder wall due to both translation motion of the piston across the piston- cylinder clearance and the piston's angular rotation about its gudgeon pin, Nakada, et. al.[5]. Piston movement across the cylinder clearance is derived by the side thrust forces acting on it, Priede $[6,7]$.

Great attention has been dedicated to reduce engine vibration in the foregoing five decades. Modeling and assessment of engine dynamics have been given considerable attention. The piston impact phenomenon has had an enormous portion of attempts aiming at modeling the impact forces and predicting the cylinder liner response Haddad [8], Ohta, et. al. [9] and Tsuda and Koizumi [10]. To achieve an accurate estimate of engine noise and vibration induced by piston slap, Vora and Ghosh [11], it is crucial to achieve an accurate estimate of the impact slapping force. Investigations of piston slap included both experimental and analytical attempts [6]. 
Study of piston design and its motion has also taken great deal of attention too, Nakada et. al. [5].

Ghazy and Emira [12] presented a model to simulate piston impact phenomena using the liner to engine block cross mobility. They used the model to predict the engine vibration velocity response. The impact excitation of the piston is a complex phenomenon. This complexity is overwhelmed by other factors such as the time-varying transfer properties, severe reverberation and dispersion occurring inside the engine structure.

There is a mutually dependent correlation of the inner-cylinder working process, mechanical system and the vibration response of the engine. Because of the widespread mechanical and fluid impacts, severe reverberation and dispersion occur inside the engine. This correlation is almost completely submerged in the 'chaotic' response waveform [2]. Locating and identifying this correlation from the complex vibration response will possess importance, both in the engine's performance evaluation and dynamic behavior analysis.

To accurately estimate the engine vibration; and consequently noise, it is required to take into consideration as much as possible the effect of the factors influencing the piston slap. The most important factors influencing piston slap include piston dynamics Wang[13], piston-cylinder clearance, piston's center of gravity offset [8], cylinder liner configurations, mobility between cylinder and engine block [12], ..etc. In this model, the non linearity due to the impacting transient when the piston assembly contacts the cylinder wall over the piston-cylinder clearance is taken into considerations. Accurate estimation of engine vibration has a great importance in estimating and studying engine noise [14].

\section{PISTON-SLAP ANALYSIS}

Piston slap is a momentary collision event existing in the reciprocating engine. It plays an imperative role in the engine wall vibration. The piston; driven by the in-cylinder combustion force, moves along the cylinder axis; as shown in Fig.1a, while the crankshaft is rotating with a relatively constant speed mainly maintained by the flywheel. Meanwhile, due to the periodically changing pendulum angle " $\psi$ " of the connecting rod, a periodically changing side-thrust (Fs) is decomposed from the inclined connecting rod axial load (Fcon.rod), reacting the combustion pressure and inertial force $(\mathrm{Fv}=\mathrm{Fg}-\mathrm{Fi})$ of the moving piston assembly. This force pushes the piston assembly from one side of the cylinder wall skipping onto the other side, so as to induce an unceasing slap impact on the cylinder wall [15]. Predictably, existence of the piston clearance amplifies this impact effect. Further investigating the dynamics of the crank-piston system as shown in Fig.1b, the crankshaft can be taken to be rotating at a uniform angular speed " $\omega$ ". Based upon this assumption, the exact expression for the piston displacement " $y_{\mathrm{P}}$ " in terms of the crank angle " $\varphi=\omega t$ " can be derived as follows:

$y_{p}=r(1-\cos \omega t)+l\left(1-\sqrt{1-\lambda^{2} \sin ^{2} \omega t}\right)$

where: $\lambda=r / l$, " $r$ " is the crank radius, and " $l$ " is the length of the connecting rod.

Furthermore, Eq. (1-a) can be simplified into its first-term approximation form

$y_{p} \cong r(1-\cos \omega t)+0.5 \lambda^{2} \sin ^{2} \omega t$

The velocity and acceleration follow from the displacement by differentiation:

$$
\begin{aligned}
& \dot{y}_{p} \cong r \omega(\sin \omega t+0.5 \lambda \sin 2 \omega t), \\
& \ddot{y}_{p} \cong r \omega^{2}(\cos \omega t+\lambda \cos 2 \omega t)
\end{aligned}
$$

Based upon the above derivations, the sidethrust force of the piston on the cylinder wall 
is further decomposed from the longitudinally acting combustion force $F_{\mathrm{g}}$ and inertial force of the moving piston assembly:

$F_{\mathrm{i}}=m_{1} r \omega^{2}(\cos \omega t+\lambda \sin \omega t)$, with " $m_{1}$ " being the equivalent mass of the piston assembly.

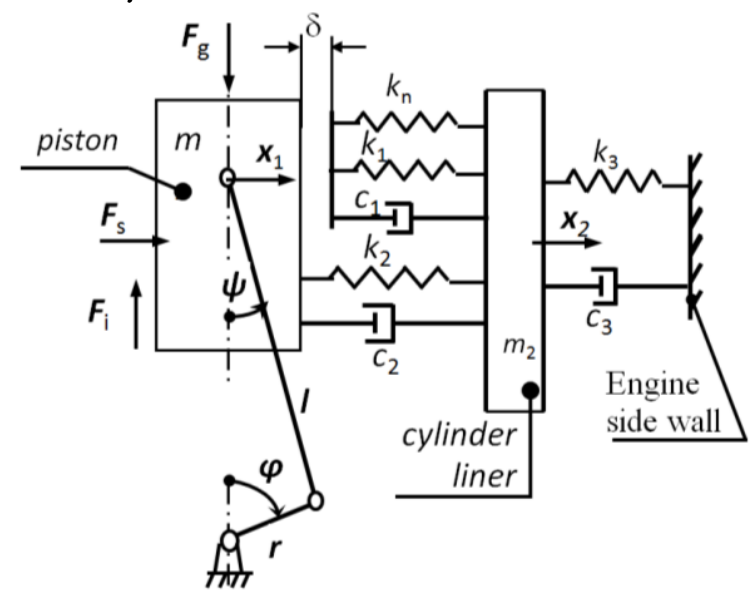

Fig. 1a: Piston-liner dynamic model

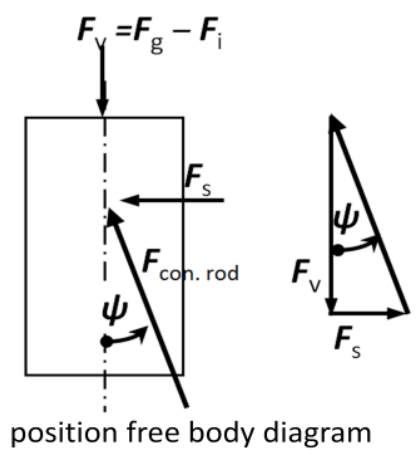

Fig. 1.b. Piston force analysis

Due to the periodically changing pendulum angle of the connecting rod, the side-thrust force is also changing periodically, with a periodic term $\sin \omega t / \sqrt{1-\lambda^{2} \sin ^{2} \omega t}$ which pushes the piston assembly from one side of the cylinder wall skipping onto the other side. Mathematically; referring to Fig.1, this sidethrust force can be derived as following:

$$
\begin{aligned}
& l \sin \psi=r \sin \varphi, \quad \cos \psi=\sqrt{1-\sin ^{2} \psi}, \\
& F_{s}=\left(F_{g}-F_{I}\right) \tan \psi, \\
& F_{s}=\left(F_{g}-F_{I}\right) \lambda \sin \omega t / \sqrt{1-\lambda^{2} \sin ^{2} \omega t} \\
& =\left[F_{g}-m_{1} r \omega^{2}(\cos \omega t+\lambda \cos 2 \omega t)\right] \lambda
\end{aligned}
$$

$$
\sin \omega t / \sqrt{1-\lambda^{2} \sin ^{2} \omega t}
$$

By introducing the physical parameters and the cylinder combustion pressure wave form the side-thrust force can be simulated. Fig.2 shows two groups of simulated side thrusts, emphasizing the influence of the inertia force. Fig.2.a shows the influence of changing the engine rotation speed at full load, while Fig.2.b shows the effect of the engine load at $2100[\mathrm{rpm}]$. As can be seen, these results conclude that the side-thrust force; as well as the piston-slap impacts, is sensitively changing with different combinations of the combustion pressure and inertia force of the piston assembly. From this point, these simulations reveal the necessity of further investigating into the structural transient response caused by the piston-slap impacts.

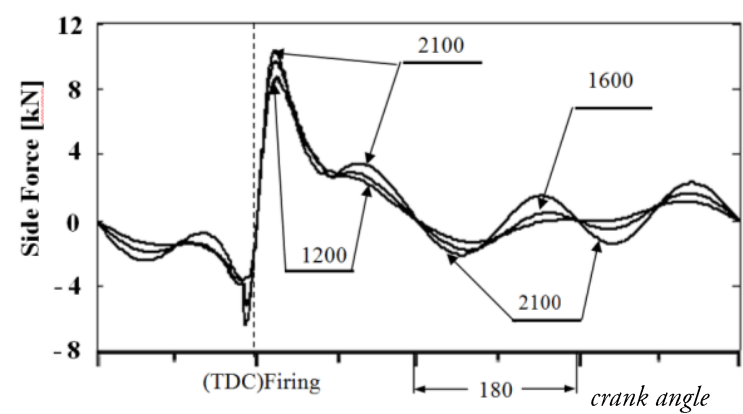

Fig. 2.a. Calculated side thrust force at different engine speeds

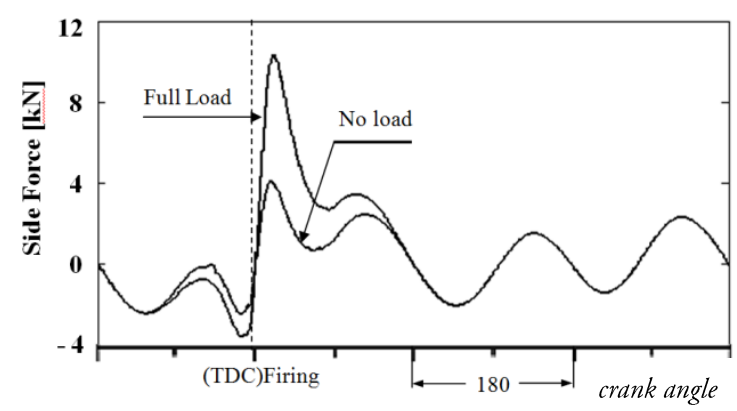

Fig. 2.b. Calculated side thrust force at different engine loads

\section{PISTON-SLAP MODELING}

The existence of the piston clearance amplifies the slap impacting effect; also the structural response of the cylinder wall caused by these 
impacts further applies complex influences on the intensities and occurrences of the slapimpact waveform. To have a detailed investigation into this situation, a two-degreeof-freedom nonlinear model for the pistoncylinder system is developed. In this model, the piston assembly is simplified into a lumped mass $\mathrm{m}_{1}$, with displacement $\mathrm{x}_{1}$. The piston is held in position by the elastic piston rings between it and the cylinder wall, with stiffness $\mathrm{k}_{2}$. Another coupling between the piston assembly and the cylinder wall is through the existence of the piston clearance " $\delta$ " ( $\delta$ is set to $0.1,0.4,0.8$ and $1.2[\mathrm{~mm}])$, which is the major nonlinear element of the system and is the cause of slap impacts. Considering the impacting transient when the piston assembly contacts the cylinder wall over the piston clearance $\delta$; which represents a non-linear dynamic term, and according to Wiggins[16] and Tabor[17] a nonlinear contacting stiffness element $\mathrm{k}_{\mathrm{n}} \mathrm{x}^{3}$ is proposed. This nonlinear stiffness (mainly for the impacting transient) is coupled with a linear stiffness $\mathrm{k}_{1}$ (during and after the impacting transient), is attached to the connection between the piston assembly and the cylinder wall $[15,18]$.

The cylinder wall assembly with lumped mass $m_{2}$ and displacement $x_{2}$ represents the second degree of freedom of the suggested system. The cylinder wall assembly is considered as rigidly constructed along the direction of piston movement, with lower linear stiffness connection $k_{3}$ between the cylinder wall and engine casing through the flexible supporting points.

Considering the lubricant's damping effect between the piston assembly and cylinder wall, viscous dampers $c_{1}, c_{2}$ and $c_{3}\left(\xi_{\mathrm{J}}=\mathrm{c}_{\mathrm{J}} / \mathrm{c}_{\mathrm{cr}}\right.$, where

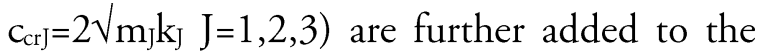
different degrees of freedom of the system.
Based on this, a corresponding differential equation is derived as:

$$
\begin{aligned}
& m_{1} \ddot{x}_{1}+c_{2}\left(\dot{x}_{1}-\dot{x}_{2}\right)+k_{2}\left(x_{1}-x_{2}\right)=P_{s} x_{1}-x_{2}<\delta \\
& m_{2} \ddot{x}_{2}+c_{2}\left(\dot{x}_{2}-\dot{x}_{1}\right)+c_{3} \dot{x}_{2}+k_{2}\left(x_{2}-x_{1}\right)+k_{3} x_{2}=0
\end{aligned}
$$

$$
\begin{aligned}
m_{1} \ddot{x}_{1} & +\left(c_{1}+c_{2}\right)\left(\dot{x}_{1}-\dot{x}_{2}\right)+\left(k_{1}+k_{2}\right)\left(x_{1}-x_{2}\right) \\
& -k_{1} \delta+k_{n}\left(x_{1}-\delta-x_{2}\right)^{3}=P_{s} \quad x_{1}-x_{2}<\delta \\
m_{2} \ddot{x}_{2} & +\left(c_{1}+c_{2}\right)\left(\dot{x}_{2}-\dot{x}_{1}\right)+c_{3} \dot{x}_{2}+\left(k_{1}+k_{2}\right)\left(x_{2}-x_{1}\right) \\
& +k_{1} \delta+k_{3} x_{2}+k_{n}\left(x_{2}+\delta-x_{1}\right)^{3}=0
\end{aligned}
$$

According to nonlinear dynamics [8,9], Eqs. (3-a and 3-b) express a hard stiffness problem with sectional linearity. By using the RungeKutta numerical integration procedure [18], the model is evaluated with $F_{s}=0$. Fig. 3 shows the calculated portraits of the vibration system at two different cases. For the case $\delta=0$ (Fig.3.a), both the piston and the liner move together.

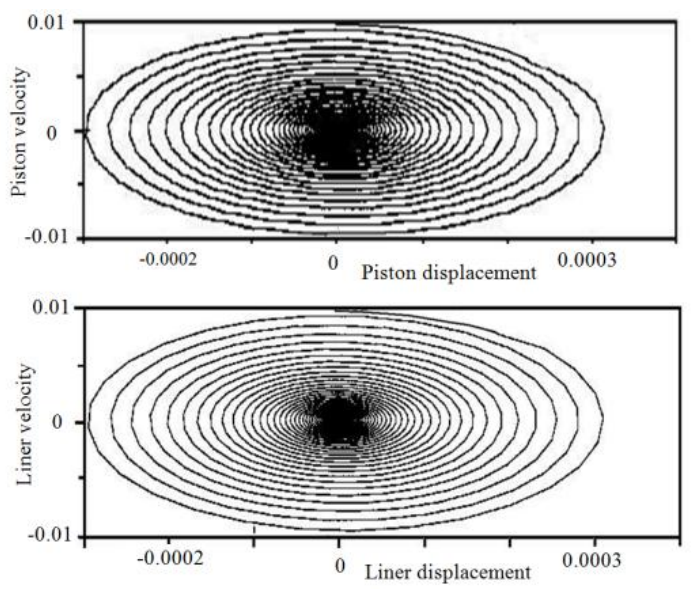

Fig. 3.a. Velocity versus displacement of both the piston and the liner, for the case $\delta=0$ with a piston initial velocity of $0.1[\mathrm{~m} / \mathrm{s}]$

For this case although the piston is given an initial velocity of $0.1[\mathrm{~m} / \mathrm{s}]$, both masses (the piston and the liner) move with a virtual velocity of $0.011[\mathrm{~m} / \mathrm{s}]$, which is given by:

$v^{\prime}=m_{1} v_{\text {piston }} /\left(m_{1}+m_{2}\right)$

Fig.3.b shows the portrait for the case with $\delta=5[\mathrm{~mm}]$. In such case, the piston does not hit the liner, and the piston moves within the gap. 

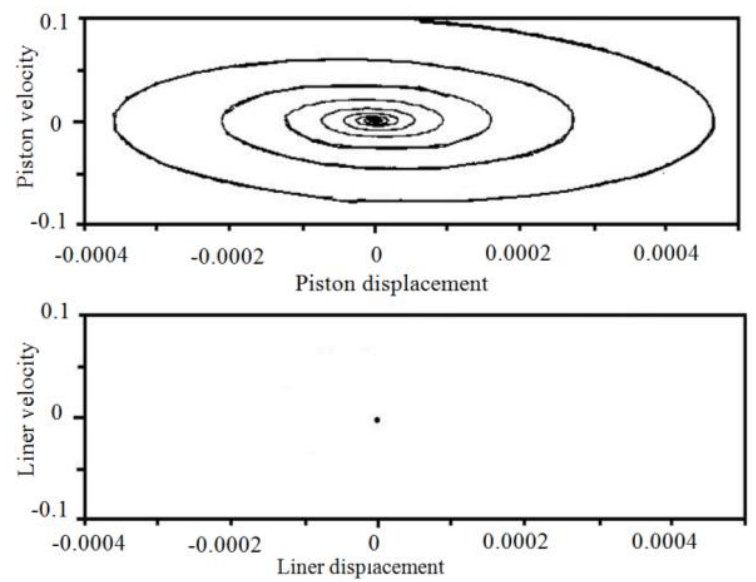

Fig. 3.b. Velocity versus displacement of both the piston and the liner, for the case $\delta=5[\mathrm{~mm}]$, with a piston initial velocity of $0.1[\mathrm{~m} / \mathrm{s}]$

\section{CASE STUDY}

Fig.4 shows a typical numerical simulation of the liner vibrational response due to piston slap. There are induced abrupt transients occurring when the piston displacement changes from positive to negative (or vice versa), this means an occurrence of a pistonslap impact on a definite position along the cylinder wall. Phase delays are clearly noticed between the vibration response and the exciting force, mainly caused due to the existence of the piston clearance.

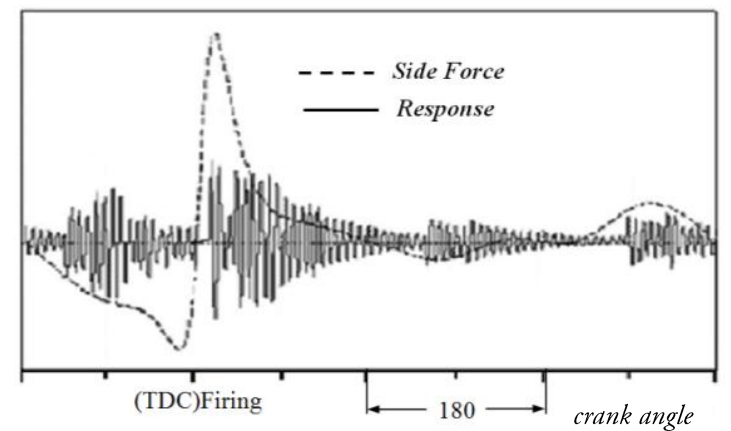

Fig.4. A typical simulated liner vibrational response due to piston slap

Investigating the simulation results of Fig.4, one can find that, with different combination of the combustion pressure and inertia force of the piston assembly, the combined sidethrust force $F_{\mathrm{s}}$ presents a significant change in its waveform and so do the occurrences of the piston-slap impacts. This means, the number of piston-slap impacts as well as the time of occurrence in a working cycle can be taken as potential monitoring indicators of the engine performance and working conditions. Engine with more slap impacts caused by the inertia force will be in a worse performance or working condition than another one with more slap impacts caused by the combustion pressure.

The simulated vibration response of the cylinder wall excited by the slap impacts are shown in Figs.5-8. The liner response differs according to the engine running conditions (speed and load). In Figs.5 and 6; at high speed $(2100 \mathrm{rpm})$ situation, the relatively long periodic oscillation of the preceding slap response often submerges the abrupt starting of the following one. At such a case, the effect of the inertia force is dominant at light-load condition (Fig.6). At lower engine speeds, at light load and heavy load, the slap-induced transients are clear.

The effect of piston to liner clearance, at 1200 rpm engine speed, is shown in Figs.7 and 8. The time delay of the slap-induced response increases with an increase of the piston clearance; as is shown in the figures. This reveals a dependent relationship between the slap-induced response and the piston clearance which has an important engineering implication. In a theoretical sense, it also gives a strong verification of the developed nonlinear model as expressed in Eq. (3).

The simulation reveals a high resemblance between the simulated liner response at the full load running condition, at different engine speeds (Fig.5) and the measured slapinduced vibration response at the same running conditions (Fig.9). The simulation; also, reveals a high resemblance between the simulated liner response at engine speed of $1600[\mathrm{rpm}]$, for different load conditions (full 
and no load) (Figs.5 and 6) and the measured slap-induced vibration response at the same running conditions (Fig.10).

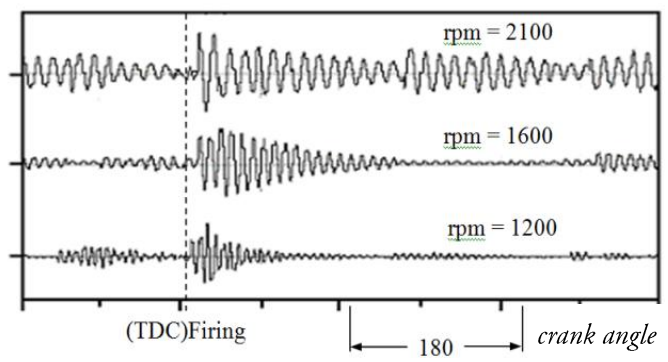

Fig. 5. Liner velocity response at $\delta=1.2 \mathrm{~mm}$, full load

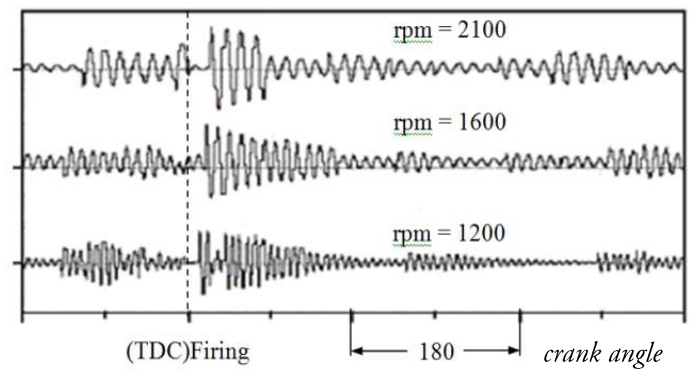

Fig. 6. Liner velocity response at $\delta=1.2 \mathrm{~mm}$, no load

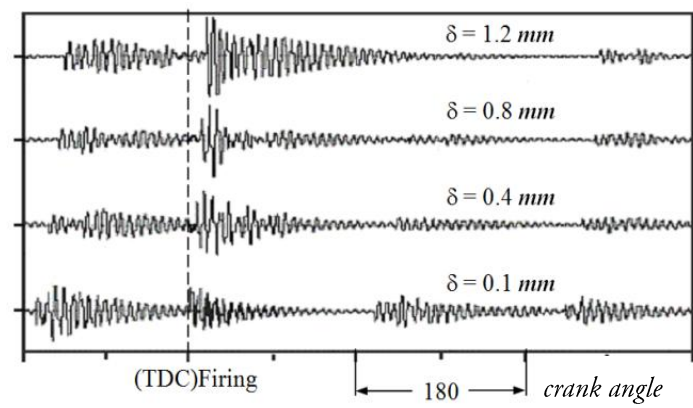

Fig. 7. Liner velocity response at $1200 \mathrm{rpm}$ full load.

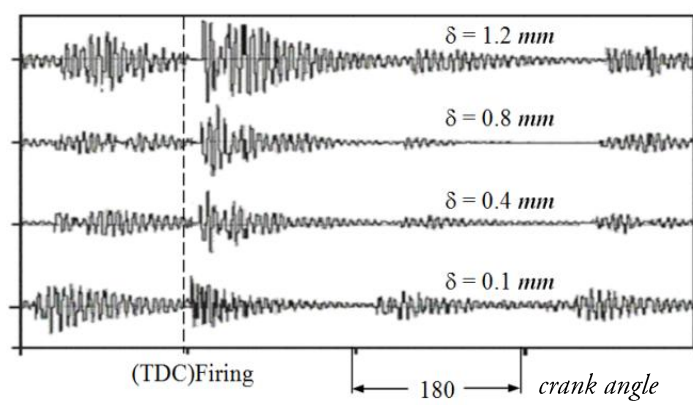

Fig. 8. Liner velocity response at $1200 \mathrm{rpm}$ no load.

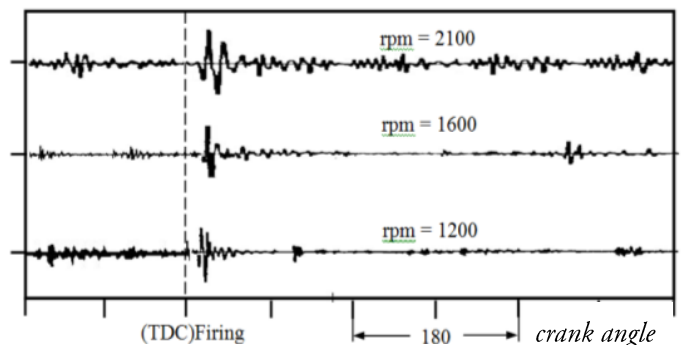

Fig. 9. Measured liner response at full load, (Priede, [19])

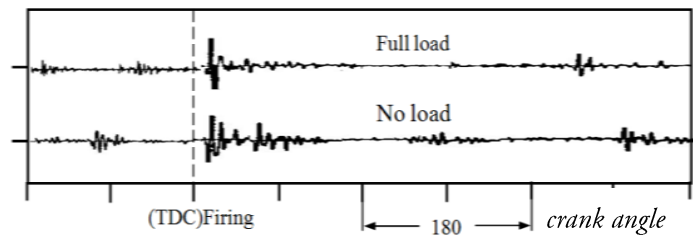

Fig. 10. Measured liner response at 1600rpm, (Priede, [18])

These figures show a good coincidence of the main slap induced response. The correlation between the inner cylinder piston impact and the slap induced vibration response is proven to be appropriate. This simulation of the engine's inner cylinder dynamic behavior can be applicable to evaluate the engine's performance.

\section{CONCLUSION}

The work presents an effective tool for the reciprocating engine's dynamic analysis. By correlating the piston-slap phenomenon with the slap-induced vibration response, an applicable approach for the inner-cylinder vibration simulation is presented. This will be further used to predict the engine's outer surface.

The results show a correlation between the piston-slap impact and the slap-induced vibration response. This correlation; of the simulated engine's in-cylinder dynamic behavior, prove the validity of the proposed nonlinear model.

As the theoretical description of the pistonslap mechanism is proven to be reasonable through numerical simulation, this will be helpful in further investigation into the piston-slap phenomenon and relevant dynamic problems.

The proposed non linear dynamic model developed reasonably describes the mutually dependent correlations of the in-cylinder excitations, piston-cylinder wall structural properties, and its vibration response.

Although this model is simple and brief (for example, the rotational freedom of the piston 
assembly as well as the inner-cylinder thermal effect is not considered), it supplies a framework for similar system modeling (such as bearing impact).

\section{REFERENCES}

[1] Kim, J.T., Lyon, R.H., "Spectral analysis as a tool for robust processing, reverberation and detection of transients", Journal of Mechanical System and Signal Processing, Vol. 6 (1), 1992, pp.1-15.

[2] Lyon, R.H., Machinery Noise and Diagnostics, Butterworths, London, 1987.

[3] Cemple, C., Vibroacoustic Condition Monitoring, Ellis Horwood, Chichester, 1994.

[4] White, R.G., Noise and Vibration, Ellis Horwood Publishers, 1982.

[5] Nakada, T., Yamamoto, A. and Abe, T., "A Numerical Approach for Piston Secondary Motion Analysis and its Application to the Piston Related Noise”, SAE paper 972043, 1997.

[6] Priede, T., "In Search of Origins of Engine Noise- An Historical Review", SAE Paper 800534, 1980.

[7] Priede, T., "The Problem of Noise of Engines in Different Vehicle Groups", SAE Paper 750795 , 1975.

[8] Haddad, Sam. D., and Tjan Kektjen, "Analytical Study of Offset Piston and Crankshaft Designs and the Effect of Oil Film on Piston Slap Excitation in a Diesel Engine”, Mechanism \& Machine Theory, Vol.30(2), 1995, pp.271-284.

[9] Ohta, K., Irie,Y., Yamamoto, K. and Ishikawa, H., "Piston Slap Induced Noise and Vibration of Internal Combustion Engines", SAE paper 870990, 1987.

[10] Tsuda, K., and Koizumi, T., "Mechanics of Piston Slap", JSME Transaction, Vol.40 (334), 1974.

[11] Vora, K.C, and Ghosh, B., "Vibration Due to Piston Slap and Combustion in Gasoline and Diesel Engines", SAE Preprints No.244, 1991, pp.167-177.

[12] Ghazy, M.R. and Emira, M.N, "Prediction of Engine Noise due to Piston Slap”, Ain Shams Univ, Faculty of Engineering, Scientific Bulletin, Vol.39(2), 2004, pp.795-810.
[13] Wang, Yi-Ming, "The dynamics of a slider crank mechanism with initially curved coupler under two-component parametric resonance", Journal of Sound and Vibration, Vol.280, 2005, pp. 815-835.

[14] Philipp Sellerbeck, et al, "Improving Diesel Sound Quality on Engine Level and Vehicle Level-a Holistic Approach", SAE 2007-01-2372, 2007.

[15] Tabor, M., Chaos and Integrability in Nonlinear Dynamics: An Intoduction, New York, Wiley, 1989.

[16] Wiggins, S., Introduction to Applied Nonlinear Dynamical Systems and Chaos, New York, Springer-Verlag, 1990.

[17] Den Hartog, J.P., Mechanical Vibration, McGraw-Hill, London, 1968.

[18] Cartmel, M.I, Introduction to Linear, Parametric, and Nonlinear Vibrations, Chapman \& Hall, London, 1990.

[19] Priede, T., "In Search of Origins of Engine Noise - An Historical Review", SAE 800534, 1980. 


\section{نموذج غير خطي يحاكي أداء المحرك طبقاً لصفع المكبس}

$$
\begin{aligned}
& \text { نديم أحمد عمبرة1، محمد رياض علي غازي2 } \\
& 1 \text { قسم تقنية الهندسة الميكانيكية، كلية ينبع الصناعية، الممكلة العربية السعودية }
\end{aligned}
$$

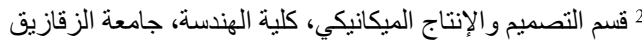

الملخص:

إن صفع المكبس هو ظاهرة خبط لحظي تحدث في المحركات الترددي، وهي تمثل أحد الأسباب الرئيسية للإهتز از في المحرك. و هذا البحث يقدم أنموذج نظري للربط بين خبط المكبس والإهتزاز الناتج عنه، ويبحث في إيجاد مدخل مناسب لنمذجة التصرف الديناميكي للمحرك للتنبؤ الجيد بإعتز از المحرك. وقد تمت دراسة ظاهرة خبط المكبس من وجهة نظر ميكانيكية المحرك، حيث تم وضع أنموذج غير خطي لتمثيل الإهتزاز عن خبط الككب. وقد تم تقييم إهتزاز جدار المكبس الناتج و علاقته بخبط المكبس. 